\title{
Actinide Targets for Neutron Cross Section Measurements
}

\author{
John D. Baker
}

Christopher A. McGrath

October 2006

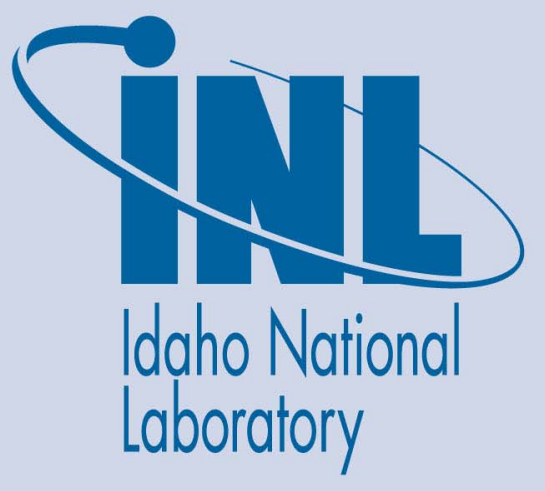

The INL is a U.S. Department of Energy National Laboratory operated by Battelle Energy Alliance 
INL/EXT-06-11834

\title{
Actinide Targets for Neutron Cross Section Measurements
}

\author{
John D. Baker \\ Christopher A. McGrath
}

October 2006

\begin{abstract}
Idaho National Laboratory
Idaho Falls, Idaho 83415
\end{abstract}

Prepared for the

U.S. Department of Energy

Office of Nuclear Energy

Under DOE Idaho Operations Office

Contract DE-AC07-05ID14517 


\title{
Actinide Targets for Neutron Cross Section Measurements
}

\author{
INL/EXT-06-11834
}

October 2006

Approved by

Type 1st persons name here

Date

Type 2nd persons name here

Date

Type 3rd persons name here

Date 



\begin{abstract}
The Advanced Fuel Cycle Initiative (AFCI) and the Generation IV Reactor Initiative have demonstrated a lack of detailed neutron cross-sections for certain "minor" actinides, those other than the most common $\left({ }^{235} \mathrm{U},{ }^{238} \mathrm{U}\right.$, and $\left.{ }^{239} \mathrm{Pu}\right)$. For some closed-fuel-cycle reactor designs more than $50 \%$ of reactivity will, at some point, be derived from "minor" actinides that currently have poorly known or in some cases not measured $(\mathrm{n}, \gamma)$ and $(\mathrm{n}, \mathrm{f})$ cross sections. A program of measurements under AFCI has begun to correct this. One of the initial hurdles has been to produce well-characterized, highly isotopically enriched, and chemically pure actinide targets on thin backings. Using a combination of resurrected techniques and new developments, we have made a series of targets including highly enriched ${ }^{239} \mathrm{Pu},{ }^{240} \mathrm{Pu}$, and ${ }^{242} \mathrm{Pu}$. Thus far, we have electrodeposited these actinide targets. In the future, we plan to study reductive distillation to achieve homogeneous, adherent targets on thin metal foils and polymer backings. As we move forward, separated isotopes become scarcer, and safety concerns become greater. The chemical purification and electodeposition techniques will be described.
\end{abstract}





\section{CONTENTS}

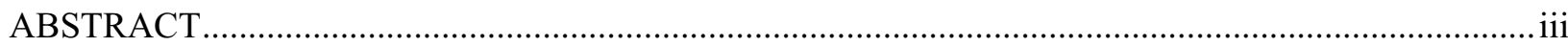

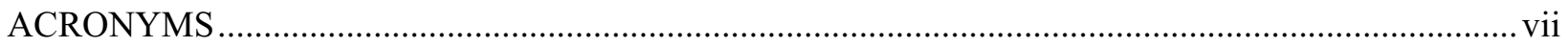

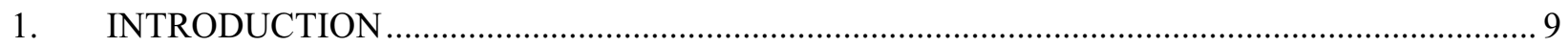

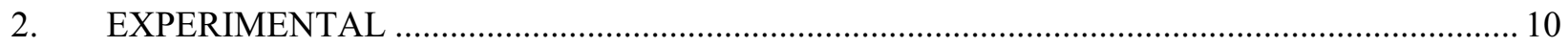

2.1 Preparation of Reagents and Target Backing Foils ...................................................... 10

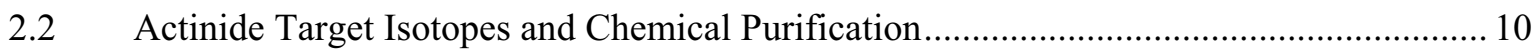

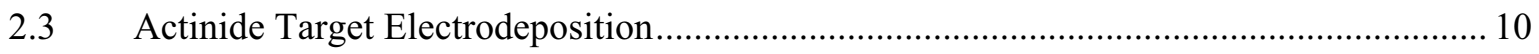

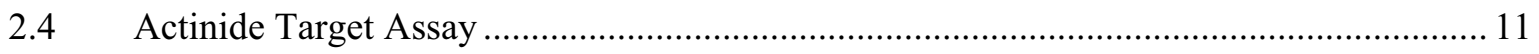

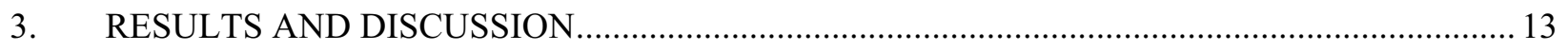

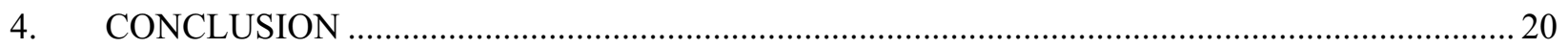

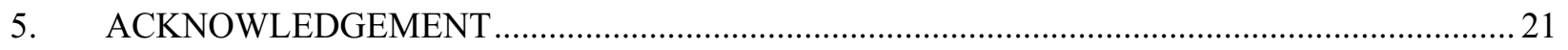

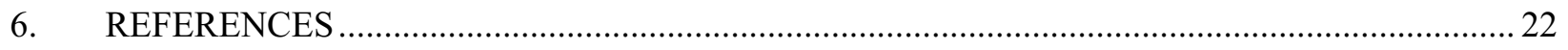

FIGURES

1. Gamma ray spectra of ${ }^{240} \mathrm{Pu}$ before and after chemical purification............................................... 12

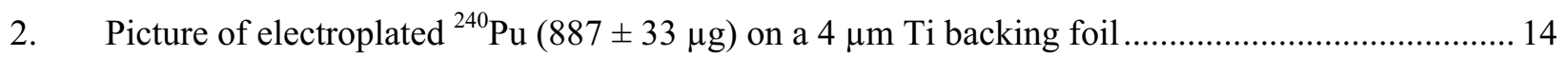

3. Picture of DANCE Radioactive Target Holder containing ${ }^{240} \mathrm{Pu}$ target ........................................ 15

4. Schematic of LANSCE accelerator and spallation neutron source experimental areas indicating location of DANCE detector and fission detector areas ............................................. 16

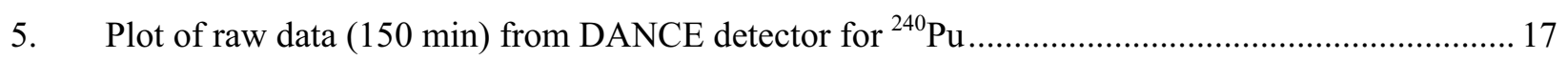

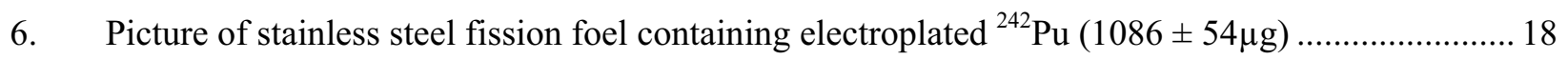

7. Plot of raw neutron induced fission data $(600 \mathrm{hr})$ from parallel plate ionization chamber for ${ }^{242} \mathrm{Pu}$

\section{TABLES}

1. Isotopic content of each of the Pu target materials...... 10

2. $\mathrm{Pu}$ Electroplating Results 11 



\section{ACRONYMS}

AFCI Advanced Fuel Cycle initiative

DOE Department of Energy

Gen-IV Generation-IV

INL Idaho National Laboratory

LANL Los Alamos National Laboratory

LANSCE Los Alamos Neutron Scattering Center

NE Nuclear Energy

NERAC Nuclear Energy Research Advisory Committee

ORNL Oak Ridge National Laboratory 


\section{Actinide Targets for Neutron Cross Section Measurements}

\section{INTRODUCTION}

The United States Department of Energy (DOE), Office of Nuclear Energy (NE) has embarked on a long-term program to significantly advance the science and technology of nuclear energy. Key aspects of the DOE-NE agenda are embodied in the Generation-IV (Gen-IV) advanced nuclear energy systems development program and in the Advanced Fuel Cycle Initiative (AFCI) program. The planned efforts involve near-term and intermediate-term improvements in fuel utilization and recycling in current nuclear power reactor systems as well as the longer-term development of new nuclear energy systems that offer much improved fuel utilization, proliferation resistance and reduced requirements for waste disposal, along with continued advances in operational safety.

One of the most important improvements will be the fundamental nuclear databases, especially the evaluated neutron interaction cross section files that serve as the foundation of all reactor system designs, operating strategies, and fuel cycle engineering activities. In particular, the new concepts for reactors and fuel cycles involve the use of transuranic nuclides that were previously of little interest, and where measured information is limited and in some cases does not exist.

There is a recognized need for improvement of the neutron cross section database for several of the actinides, especially in the case of nuclides (minor actinides) other than ${ }^{235} \mathrm{U},{ }^{238} \mathrm{U}$, and ${ }^{239} \mathrm{Pu}$, which of course already have been extensively studied and characterized. As discussed in the DOE-NE Long Term Nuclear Technology Research and Development Plan, published in June, 2000 by the DOE Nuclear Energy Research Advisory Committee (NERAC), there is a clear recognition in the U.S. community that, "Advances in reactor concept design can be expected to require additional data for basic nuclear properties, such as neutron and gamma spectral data, microscopic cross sections (and other information). The existing data base is only marginally adequate for present applications and is unlikely to be sufficient for future applications." A similar consensus exists in the international community ${ }^{1}$.

Therefore, the Idaho National Laboratory (INL) and the Los Alamos National Laboratory (LANL) have initiated a program to fabricate actinide isotope targets and measure the $(\mathrm{n}, \gamma)$ and $(\mathrm{n}, \mathrm{f})$ cross sections with neutrons in the energy range of $10^{-2}-10^{6} \mathrm{eV}$, using the DANCE detector ${ }^{2}$ (Detector for Advanced Neutron Capture Experiments) and various fission detectors ${ }^{3}$, located on collimated neutron beam lines at the Los Alamos Neutron Scattering Center (LANSCE). 


\section{EXPERIMENTAL}

\subsection{Preparation of Reagents and Target Backing Foils}

The chemical reagents were all ACS grade and solutions were made using deionized water (18 $\mathrm{M} \Omega$ ). The $2.5 \mu \mathrm{m}$ and $4 \mu \mathrm{m}$ titanium foils (99.6\% pure), used to support DANCE targets, were purchased from Goodfellow Corporation and were attached to Al rings using Devcon 5 minute epoxy \#14250. The Al rings have an O.D. of 1.6" and an I.D. of 1". VYNS, a copolymer of $90 \%$ vinyl chloride and $10 \%$ vinyl acetate was purchased from The Dow Chemical Co. Solutions of VYNS were made using cyclohexanone, as described by YAFEE ${ }^{4}$. The one-sided, fission foils are $12.5 \mu \mathrm{m}$ thick stainless steel that is sandwiched between stainless steel rings that are 7" O.D. and 6" I.D.

\subsection{Actinide Target Isotopes and Chemical Purification}

${ }^{239} \mathrm{Pu},{ }^{240} \mathrm{Pu}$ and ${ }^{242} \mathrm{Pu}$ was purchased from ORNL, isotope sales department. Each of these $\mathrm{Pu}$ isotopes was the highest enrichment available. Table 1 shows the isotopic abundance for each of these enriched isotopes on $03 / 30 / 2006$. The Pu target material was chemically purified by either the classic anion exchange technique (adsorb $\mathrm{Pu}$ (IV) to anion exchange column from $10 \underline{\mathrm{M}} \mathrm{HCL}$ or $\mathrm{HNO}_{3}$, wash with same acid and remove $\mathrm{Pu}$ by reducing acid strength to $0.1 \underline{\mathrm{M}}$ or reducing the $\mathrm{Pu}$ (IV) to $\mathrm{Pu}$ (III) with HCL/HI) or use of a TEVA-resin ${ }^{\circledR}$ anion chromatography column. These $2 \mathrm{ml}, 100-150 \mu \mathrm{m}$ particle size, resin columns were purchased from Eichrom Technologies, Inc and the purification technique is described by Horwitz .

Table 1. Isotopic content of each of the Pu target materials.

\begin{tabular}{|c|c|c|c|c|c|c|}
\hline Enriched Isotope & 238 & 239 & 240 & 241 & 242 & 244 \\
\hline${ }^{239} \mathrm{Pu}$ & 0.0345 & 99.077 & 0.881 & 0.002 & 0.005 & 0.000 \\
\hline${ }^{240} \mathrm{Pu}$ & 0.007 & 0.735 & 98.835 & 0.141 & 0.282 & 0.000 \\
\hline${ }^{242} \mathrm{Pu}$ & 0.002 & 0.016 & 0.025 & 0.012 & 99.943 & 0.002 \\
\hline
\end{tabular}

The purification of the enriched isotopic $\mathrm{Pu}$ target material, $\sim 5 \mathrm{mg}$, using the TEVA column is as follows. The Pu was dissolved in $5 \mathrm{ml}$ of warm $8 \underline{\mathrm{M}} \mathrm{HNO}_{3} / 0.01 \underline{\mathrm{M}} \mathrm{HF}$. We added $0.5 \mathrm{ml}$ of saturated $\mathrm{H}_{3} \mathrm{BO}_{3}$ to complex the fluoride ion and the solution was evaporated to dryness. The $\mathrm{Pu}$ was redissolved in $\sim 2 \mathrm{ml}$ of $2 \underline{\mathrm{M}} \mathrm{HNO}_{3}$. This solution was passed through a TEVA-resin column along with one $2 \mathrm{ml}$ rinse of the beaker. The Pu (IV) is strongly adsorbed to the resin while Am (III) and U (VI) does not. The

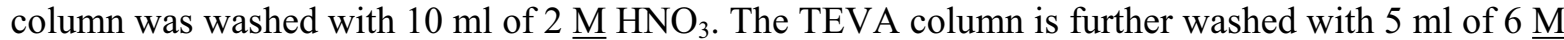
$\mathrm{HCl}$ which removes any $\mathrm{Th}(\mathrm{IV})$ and displaces the $\mathrm{HNO}_{3}$. Finally, the $\mathrm{Pu}$ is removed from the column

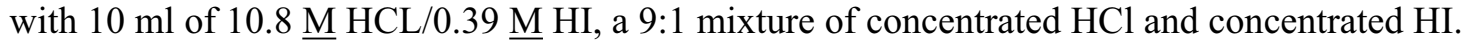

An example of the purification of ${ }^{240} \mathrm{Pu}$ (the Pu isotope with the most ${ }^{241} \mathrm{Pu}$ ) is shown in Figure 1. It is evident that the ${ }^{241} \mathrm{Am}$, the dominant gamma-ray emitting impurity, has been reduced to a not detected level, a factor of $\sim 10^{5}$. This chemical purification was performed for each enriched $\mathrm{Pu}$ isotope prior to target fabrication.

\subsection{Actinide Target Electrodeposition}

We used the electroplating technique described by MAYA ${ }^{7}$. Maya used $0.4 \underline{\mathrm{M}}\left(\mathrm{NH}_{4}\right)_{2} \mathrm{SO}_{4}$ adjusted to $\mathrm{pH} 2.6$ to electroplate $\mathrm{U}$ as the hydrated $\mathrm{UO}_{2}$ onto Ni substrates. The effluent from the TEVA column, containing $\mathrm{Pu}$ (III) in $\mathrm{HCl} / \mathrm{HI}$ was evaporated to dryness several times with concentrated $\mathrm{HNO}_{3}$ and 
redissolved in $2 \mathrm{ml}$ of $1 \underline{\mathrm{M}} \mathrm{HNO}_{3}$. We would take $0.25 \mathrm{ml}$ of this solution and very gently evaporate to dryness and then redissolve the $\mathrm{Pu}$ in $8 \mathrm{ml}$ of $0.4 \underline{\mathrm{M}}\left(\mathrm{NH}_{4}\right)_{2} \mathrm{SO}_{4}$ adjusted to $\mathrm{pH}$ 2.6. Rapidly, this solution was transferred to the electrodeposition cell, using a Ti foil for the cathode and a Pt wire, bent into a ring at the end, as the anode. The ring was parallel to the Ti cathode and $\sim 5 \mathrm{~mm}$ above it. A dc power supply provided constant current of $0.35 \mathrm{~A}\left(0.70 \mathrm{~A} / \mathrm{cm}^{2}\right)$ at $\sim 15 \mathrm{~V}$. The cell was rotated relative to the $\mathrm{Pt}$ wire during electroplating which lasted for $\sim 80$ minutes. At the end of the electroplating, but prior to turning off the voltage, $\sim 1 \mathrm{ml}$ of concentrated $\mathrm{NH}_{4} \mathrm{OH}$ was added to the electrolyte to minimize redissolution of the $\mathrm{Pu}$ hydrated oxide. The electrolyte was poured into a bottle for later recovery of unplated $\mathrm{Pu}$ as was a deionized $\mathrm{H}_{2} \mathrm{O}$ wash of the electroplating cell. Finally, the electroplated $\mathrm{Pu}$, still in the cell, was washed with ethyl alcohol and the cell was inverted to let the deposited Pu dry. Table 2 shows the results of $4 \mathrm{Pu}$ electrodepositions, one with a lesser amount of $\mathrm{Pu}$ and the last 3 are replicate with a electroplating efficiency of $\sim 70 \%$ when electroplating $\sim 1 \mathrm{mg} / \mathrm{cm}^{2}$ of $\mathrm{Pu}$.

Table 2. Pu Electroplating Results.

\begin{tabular}{|l|c|c|c|c|}
\hline Date & $4 / 19 / 2005$ & $4 / 19 / 2005$ & $4 / 20 / 2005$ & $4 / 21 / 2005$ \\
\hline $\begin{array}{l}\text { Electrolyte } \\
\text { concentration }\end{array}$ & $0.4 \underline{\mathrm{M}}\left(\mathrm{NH}_{4}\right)_{2} \mathrm{SO}_{4}$ & $0.4 \underline{\mathrm{M}}\left(\mathrm{NH}_{4}\right)_{2} \mathrm{SO}_{4}$ & $0.4 \underline{\mathrm{M}}\left(\mathrm{NH}_{4}\right)_{2} \mathrm{SO}_{4}$ & $0.4 \underline{\mathrm{M}}\left(\mathrm{NH}_{4}\right)_{2} \mathrm{SO}_{4}$ \\
\hline Acidity $(\mathrm{pH})$ & 2.6 & 2.6 & 2.6 & 2.6 \\
\hline $\begin{array}{l}\text { Mass Pu added to } \\
\text { cell }(\mu \mathrm{g})\end{array}$ & 46.2 & 577 & 577 & 577 \\
\hline Time $(\mathrm{min})$ & 60 & 79 & 0.35 & 73 \\
\hline Current $(\mathrm{A})$ & 0.35 & 0.35 & $\sim 17$ & 0.35 \\
\hline Voltage $(\mathrm{V})$ & 15.4 & 45.4 & 389 & 400 \\
\hline $\begin{array}{l}\text { Mass Pu } \\
\text { Electroplated }(\mu \mathrm{g})\end{array}$ & 40.9 & 73 & 67 & 69 \\
\hline $\begin{array}{l}\text { Percent } \mathrm{Pu} \\
\text { Electroplated }\end{array}$ & 87 & Green & Green & Green \\
\hline $\begin{array}{l}\text { Color of } \\
\text { Electroplated } \mathrm{Pu}\end{array}$ & Green & & & \\
\hline
\end{tabular}

\subsection{Actinide Target Assay}

All of the Pu targets have been assayed using a carbon window HPGe detector that has been efficiency calibrated to $2-3 \%$ from $40 \mathrm{KeV}$ to $\sim 800 \mathrm{KeV}$. The initial chemical purification and electroplating studies, including Figure 1, were analyzed using a standard Al window HPGE detector. Since the ${ }^{240} \mathrm{Pu}$ and ${ }^{242} \mathrm{Pu}$ targets are rather thick and the emitted gamma-rays are low in energy, the gamma-ray attenuation in each source was modeled and found to be $\sim 1 \%$. We have combined, in quadrature, the detector efficiency uncertainty $(3 \%)$, the source attenuation uncertainty (1\%) along with the largest emission probability uncertainty ${ }^{8}$ for the gamma-rays used in the quantification $\left(1.7 \%\right.$ for ${ }^{240} \mathrm{Pu}$ and $3.9 \%$ for ${ }^{242} \mathrm{Pu}$ ), giving a total uncertainty of $3.7 \%$ for ${ }^{240} \mathrm{Pu}$ target masses and $5.0 \%$ for the ${ }^{242} \mathrm{Pu}$ target masses. 


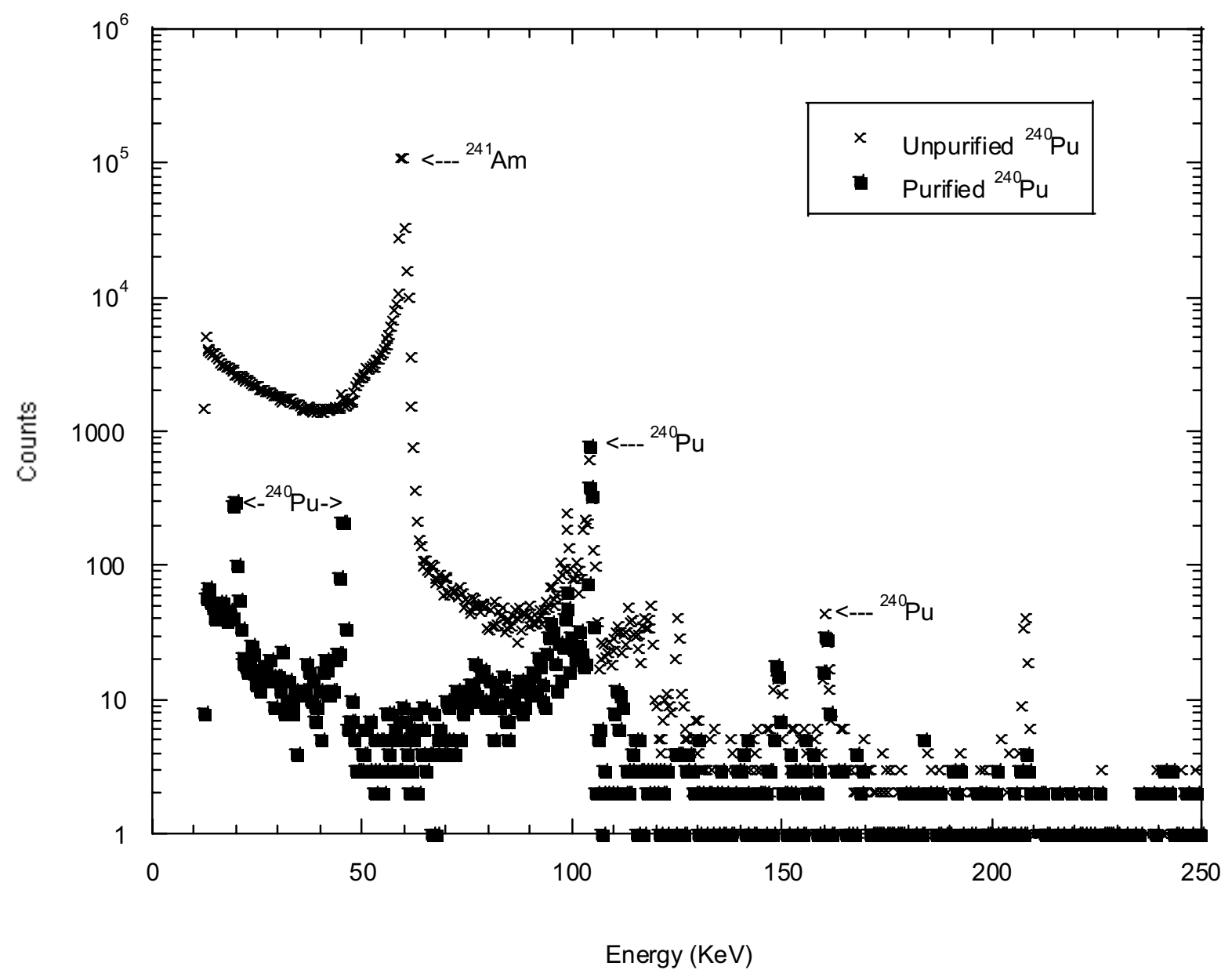

Figure 1. Gamma ray spectra of ${ }^{240} \mathrm{Pu}$ before and after chemical purification. 


\section{RESULTS AND DISCUSSION}

The DANCE neutron capture targets are typically $\sim 1 \mathrm{mg}$ in mass and $8 \mathrm{~mm}$ in diameter. The diameter was chosen such that the entire actinide deposit would be within the $10 \mathrm{~mm}$ diameter neutron beam. To date, these targets have been electroplated onto $2 \mu \mathrm{m}$ and $4 \mu \mathrm{m}$ Ti foils. All of the targets consisted of $2 \mathrm{Ti}$ foils glued together with the actinide deposit sandwiched between the foils. We did not completely glue around the circumference so as to leave a path for air to escape during evacuation in the DANCE detector. In some cases, each of the foils contained electrodeposited target material in order to increase the total mass of target material.

Figure 2 shows the picture of an uncovered ${ }^{240} \mathrm{Pu}$ electroplated DANCE target $(887 \pm 33 \mu \mathrm{g})$. Figure 3 shows an assembled ${ }^{240} \mathrm{Pu}$ DANCE target with the sandwiched foils centrally glued inside of an Al cylinder having polyimide windows on either end which acts as secondary containment while inside of the DANCE detector. This outer container is called an RTH (radioactive target holder). 


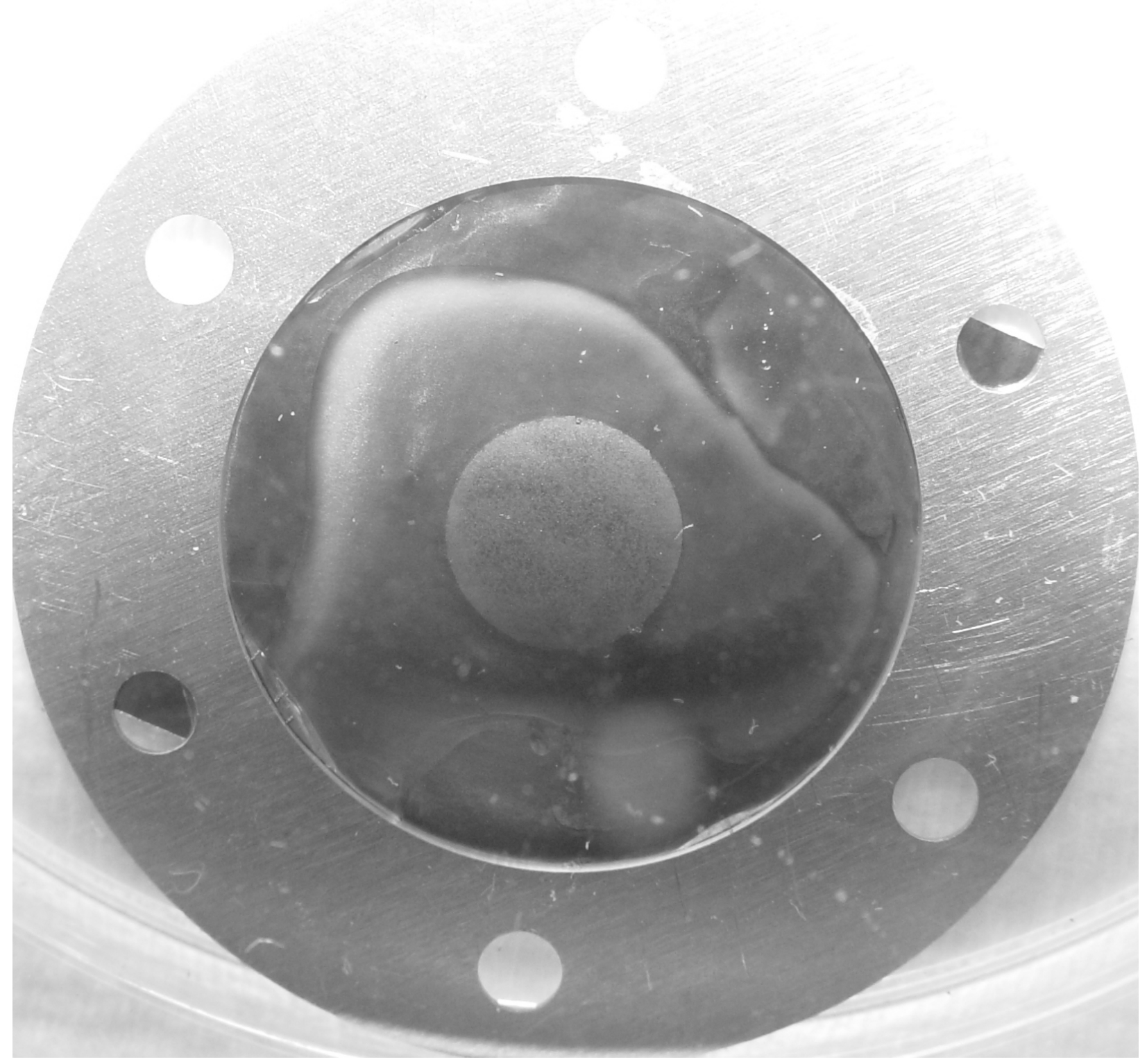

Figure 2. Picture of electroplated ${ }^{240} \mathrm{Pu}(887 \pm 33 \mu \mathrm{g})$ on a $4 \mu \mathrm{m}$ Ti backing foil. 


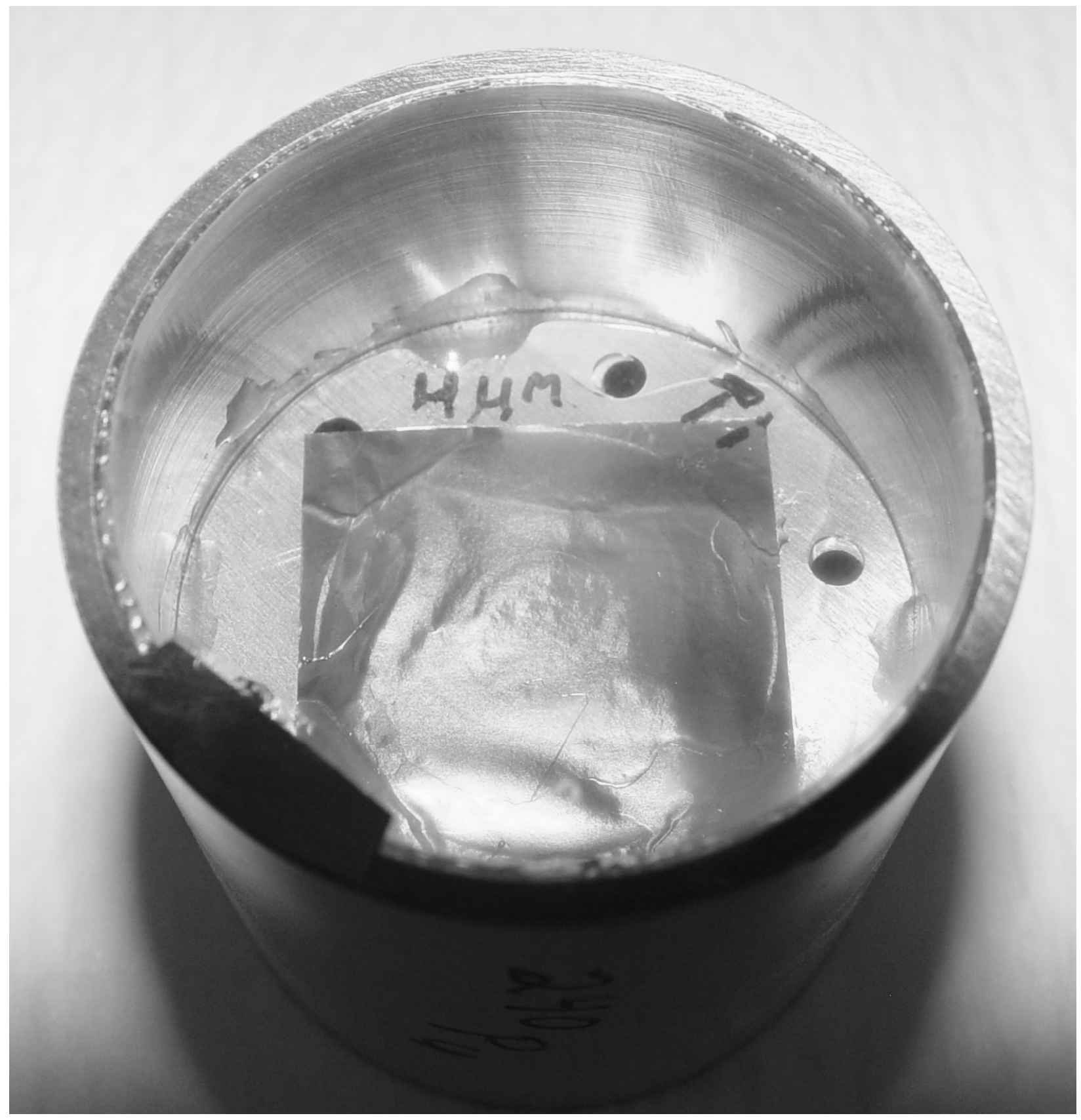

Figure 3. Picture of DANCE Radioactive Target Holder containing ${ }^{240} \mathrm{Pu}$ target.

Initially, we fabricated and shipped a ${ }^{239} \mathrm{Pu}$ target. Upon receipt at LANL, it was found to be slightly contaminated on the outside of the RTH. The DANCE detector area, as most of the detector areas at LANSCE, see Figure 4, is not setup to be a contamination area and therefore, the targets must be free from contamination. To eliminate future target dusting, both the ${ }^{240} \mathrm{Pu}$ and the ${ }^{242} \mathrm{Pu}$ deposits were covered with several drops of liquid VYNS and allowed to dry. The mass of the adherent VYNS film is $\sim 100 \mu \mathrm{g} / \mathrm{cm}^{2}$ which has little to no effect on either the incident neutrons or the exiting gamma-rays. There has been no further contamination of the targets. 


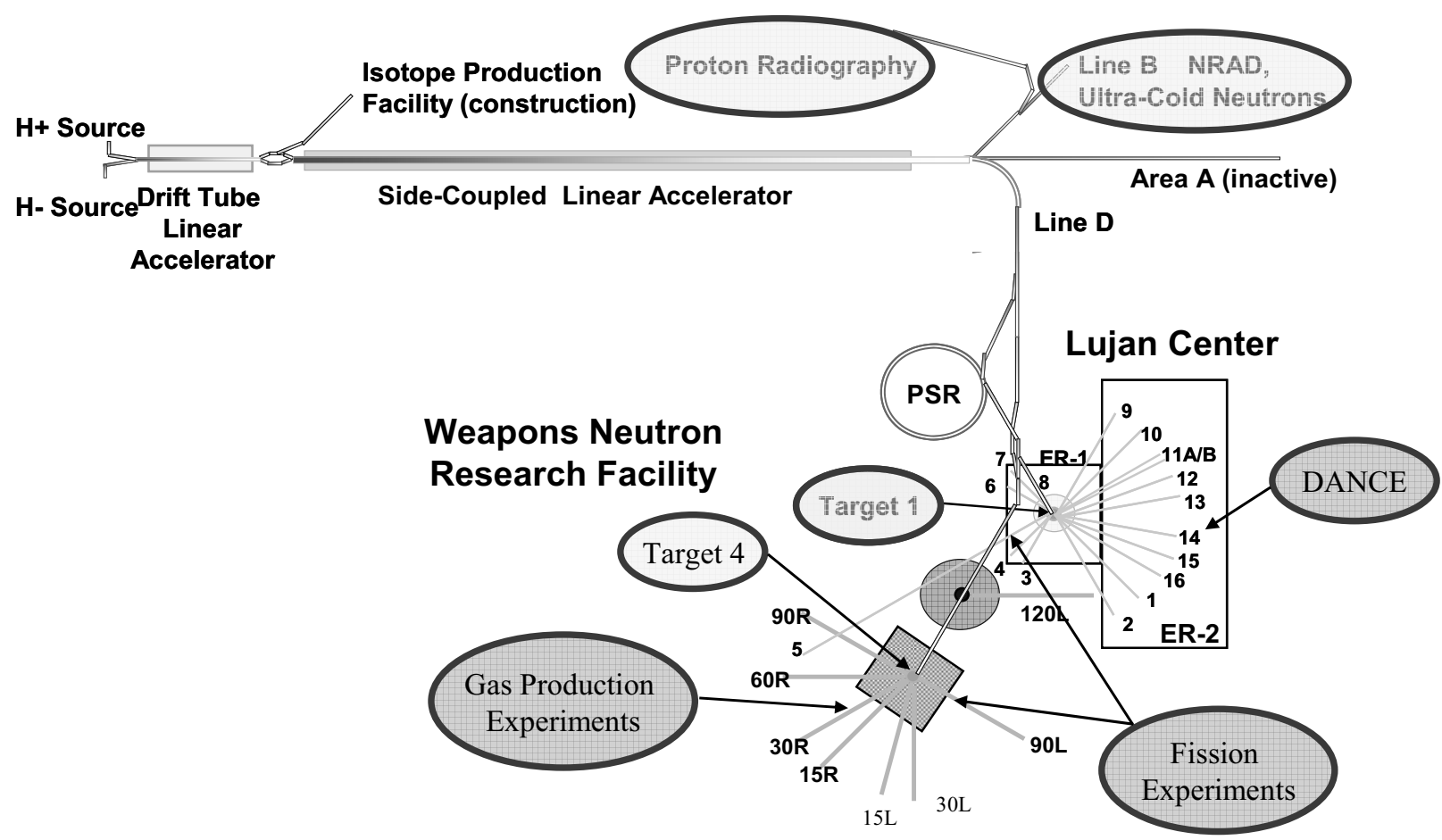

Figure 4. Schematic of LANSCE accelerator and spallation neutron source experimental areas indicating location of DANCE detector and fission detector areas.

The DANCE detector is a $4 \pi \mathrm{BaF}_{2}$ scintillator that is composed of $160 \mathrm{BaF}_{2}$ crystals. There is a $6 \mathrm{~cm}$ shell of ${ }^{6} \mathrm{LiH}$ inside of the scintillator to minimize scattered neutrons interacting with the $\mathrm{BaF}_{2}$. The neutrons come from a water moderated, tungsten spallation source and the collimation beam line is $20 \mathrm{~m}$. The detector can measure neutron capture cross sections from $0.01 \mathrm{eV}$ to $\sim 500 \mathrm{KeV}$ neutron energy. An example of the raw data that came from a DANCE measurement of ${ }^{240} \mathrm{Pu}$ is shown in Figure 5. The data set from which this graph was generated was acquired in 150 minutes. There will be a total of $\sim 12$ days of data acquisition. 


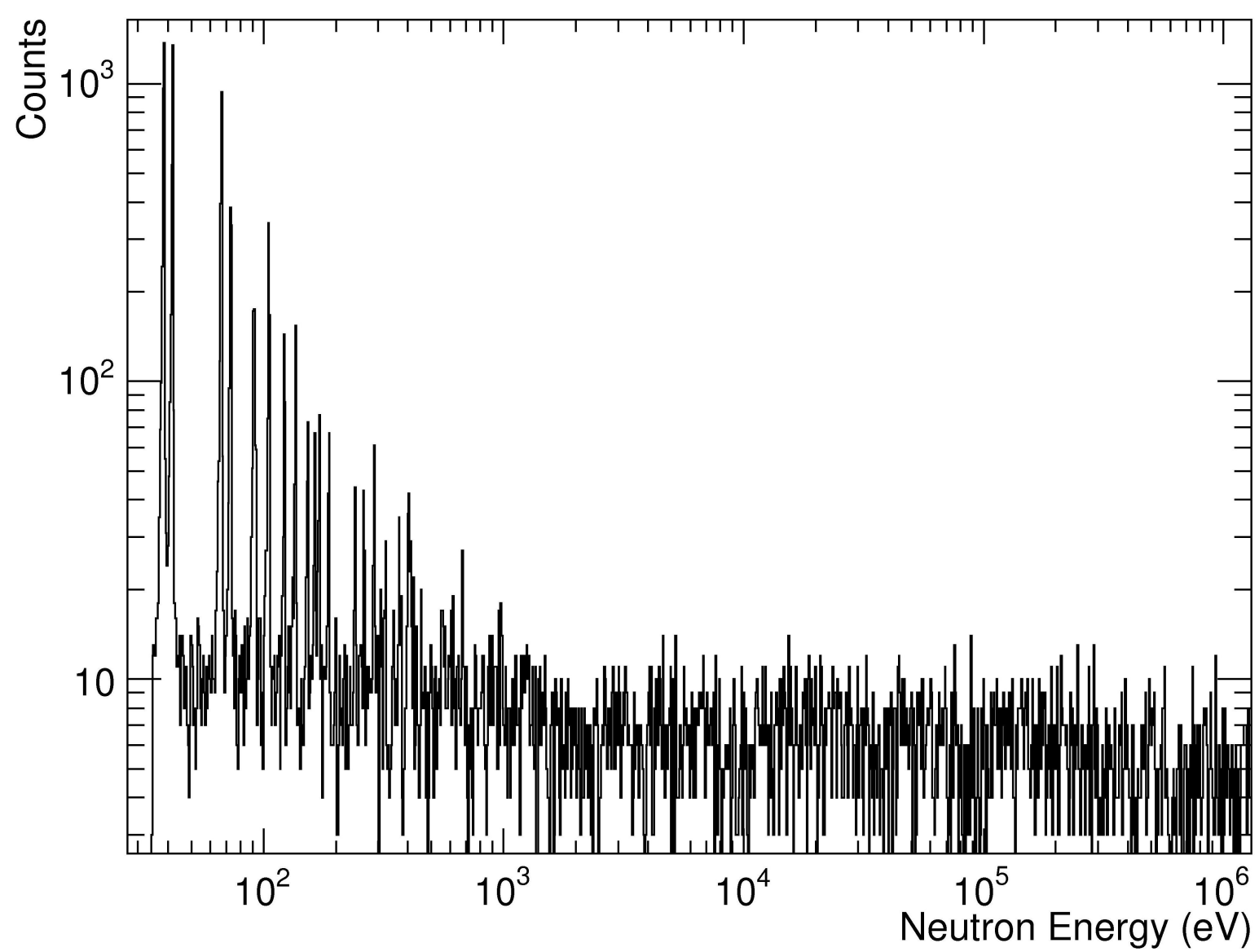

Figure 5. Plot of raw data $(150 \mathrm{~min})$ from DANCE detector for ${ }^{240} \mathrm{Pu}$.

The Pu fission target chemical purification and electroplating was identical to the DANCE targets except the fission foil deposits are $3.8 \mathrm{~cm}$ in diameter, $\sim 0.6 \mathrm{~cm}$ smaller then the neutron beam diameter. The mass density of the fission foil electrodeposited $\mathrm{Pu}$ is $\sim 200 \mu \mathrm{g} / \mathrm{cm}^{2}$ in order to minimize attenuation of the ejected fission fragments. These deposits were also covered with an $\sim 100 \mu \mathrm{g} / \mathrm{cm}^{2} \mathrm{VYNS}$ film. The VYNS deposit has been calculated to attenuate a $\mathrm{z}=53$ particle (I), $<10 \%$. Figure 6 is a picture of a ${ }^{242} \mathrm{Pu}$ fission foil $(1086 \pm 54 \mu \mathrm{g})$ covered with VYNS film. 


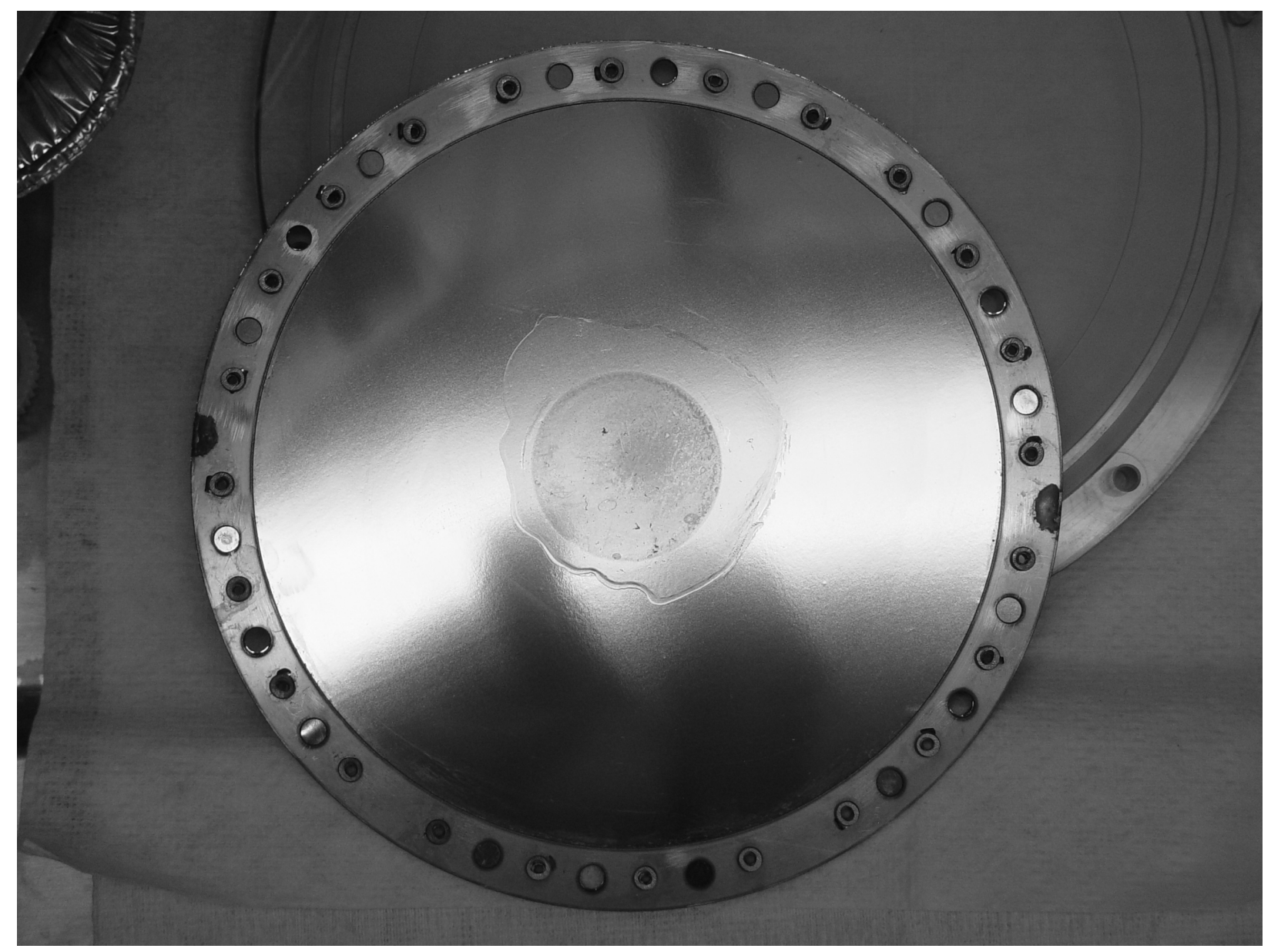

Figure 6. Picture of stainless steel fission foel containing electroplated ${ }^{242} \mathrm{Pu}(1086 \pm 54 \mu \mathrm{g})$.

The fission detector is a multiple target, parallel plate ionization chamber where each event has its energy deposition and relative timing recorded. Using two different spallation source areas, Lujan and WNR (see Figure 4), neutron fission cross section data can be measured for neutron energy from $0.01 \mathrm{eV}$ to $200 \mathrm{MeV}$. Figure 7 is a plot of $600 \mathrm{hr}$ of the raw neutron fission data versus neutron energy for ${ }^{242} \mathrm{Pu}$. 


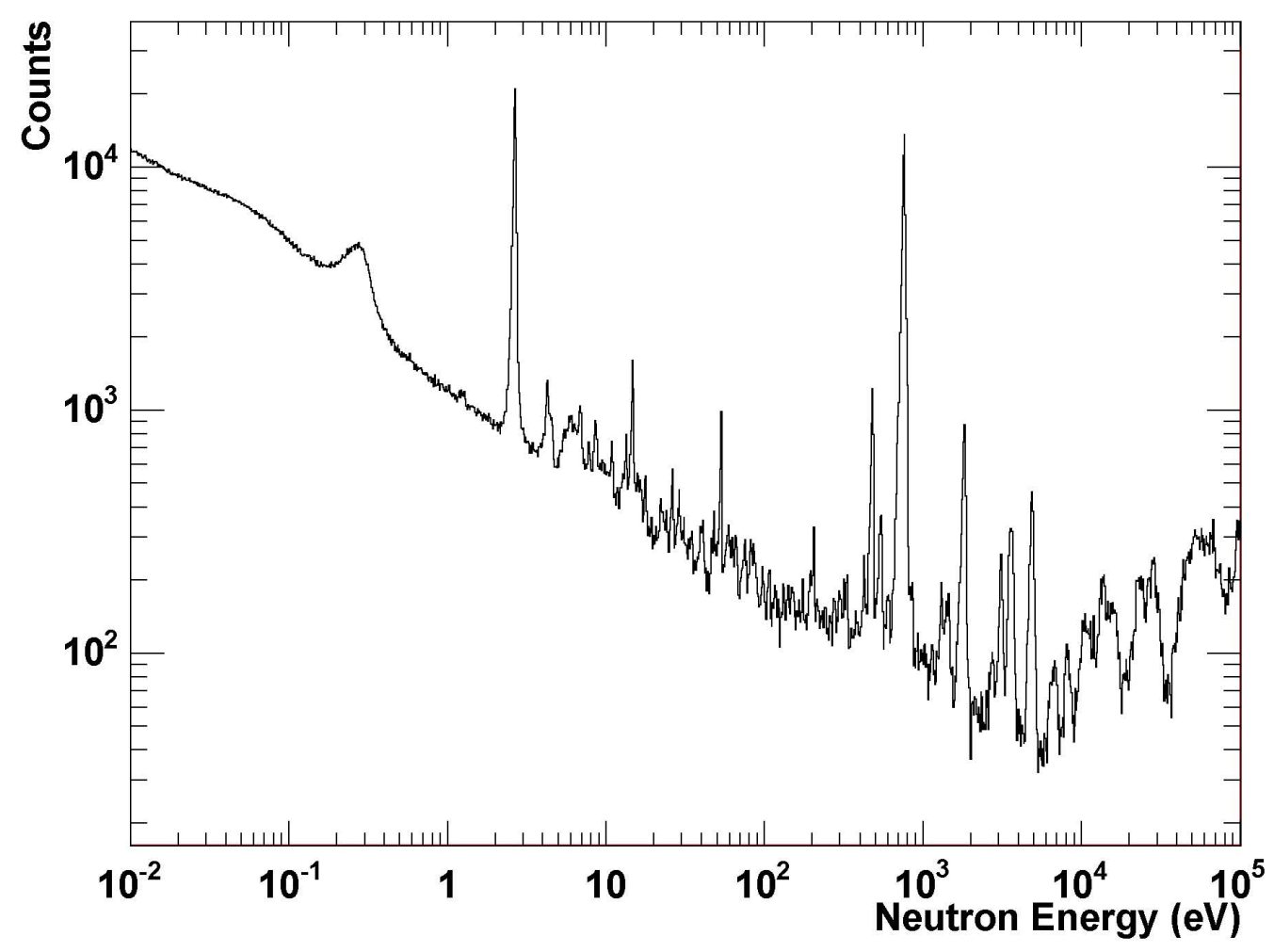

Figure 7. Plot of raw neutron induced fission data $(600 \mathrm{hr})$ from parallel plate ionization chamber for ${ }^{242} \mathrm{Pu}$. 


\section{CONCLUSION}

In order to improve the uncertainty of the neutron cross section data for the minor actinides, INL and LANL are collaborating in the fabrication of ultra pure, highly enriched actinide isotope targets and the acquisition of neutron capture and fission data. The neutron measurement experiments take place at LANSCE. Neutron fission measurements from $0.01 \mathrm{eV}$ to $\sim 100 \mathrm{eV}$ neutron energy, for threshold fission isotopes, such as ${ }^{240} \mathrm{Pu}$ and ${ }^{242} \mathrm{Pu}$, are extremely difficult with the available actinide isotopes. Neutron interaction with impurity fission isotopes, such as ${ }^{239} \mathrm{Pu}$ and ${ }^{241} \mathrm{Pu}$ (see Table 1) overwhelm the threshold fission isotopes in this energy range, even when the impurity is only $0.01 \%$. We plan to convert a small $(10 \mu \mathrm{A})$ mass separator to allow for the high enrichment of $\sim 1 \mathrm{mg}$ masses of specific actinide isotopes to improve this issue. 


\section{ACKNOWLEDGEMENT}

The authors are indebted for the use of the ${ }^{239} \mathrm{Pu},{ }^{240} \mathrm{Pu}$, and ${ }^{242} \mathrm{Pu}$ to the Office of Basic Energy Sciences, U.S. Department of Energy, through the transplutonium element production facilities at the Oak Ridge National Laboratory. Additionally, we would like to thank Khalil Spencer of LANL for measuring the isotopic analysis of the enriched Pu samples. This research was performed under the sponsorship of the U.S. Department of Energy, Office of Nuclear Energy, under DOE Idaho Operations Office Contract DE-AC07-05ID14517 and the Advanced Fuel Cycle Initiative Office of Nuclear Science and Technology of the U. S. Department of Energy, Contract AF/5806/6/AL/03. 


\section{REFERENCES}

1. T. Nakagawa, et al., "Present Status of Minor Actinide Data", Working Party on International Evaluation Cooperation of the NEA Nuclear Science Committee, NEA/WPEC-8, Organization for Economic Cooperation and Development, 1999.

2. S. A. Wender, et al, Nucl. Inst. And Meth. A. 336 (1993) 226.

3. R. Reifarth, et al, Nucl. Inst. And Meth. A. 531 (2004) 530.

4. L. Yaffe, Annual Review of Nuclear and Particle Sciences, 12, (1962) 153.

5. D. C. Hoffman, LASL Report, LA 1721, (1954) 271.

6. $\quad$ E. P. Horwitz, et al., Anal. Chim. Acta, 310 (1995) 63.

7. L. Maya, et al., J. Radioanal. Nucl. Chem., 261 (2004) 605

8. National Nuclear Data Center, Brookhaven National Laboratory, NuDat 2.2 